\title{
A IMPORTÂNCIA DOS JOGOS COOPERATIVOS NAS AULAS DE EDUCAÇÃO FÍSICA ESCOLAR NO DESENVOLVIMENTO SOCIAL DO ALUNO
}

\author{
THE IMPORTANCE OF COOPERATIVE GAMES IN SCHOOL PHYSICAL \\ EDUCATION CLASSES IN STUDENT SOCIAL DEVELOPMENT
}

\section{LA IMPORTANCIA DE LOS JUEGOS COOPERATIVOS EN LAS CLASES DE EDUCACIÓN FÍSICA ESCOLAR EN EL DESARROLLO SOCIAL DE LOS ESTUDIANTES}

\author{
Jaqueline da Silva Lima ${ }^{1}$ \\ Jeane Rodella Assunção ${ }^{2}$
}

\begin{abstract}
Resumo
A abordagem em relação aos jogos cooperativos compreende as ações coletivas baseada nos valores afetivos e no desenvolvimento social humano. Neste sentido, o presente artigo problematizou-se: Qual a importância dos jogos cooperativos nas aulas de educação escolar no desenvolvimento social do aluno? Deste modo, o estudo objetivou-se em apresentar o processo histórico, apontar as contribuições nas aulas de educação física escolar, ressaltar a importância como conteúdo da educação física escolar, relatar o papel do professor no processo de inclusão no que diz respeito aos jogos cooperativos. Em vista disso, a pesquisa origina-se de uma revisão bibliográfica. Os aspectos pesquisados mostram que os jogos cooperativos implantados nas aulas de educação física escolar influenciam de forma positiva e transformadora, levando-se em consideração o aluno como objeto principal a ser atingido, com a missão de pôr em prática toda cooperação social adquirida, independente do espaço social em que está inserido.
\end{abstract}

Palavras Chave: Educação Física; Escolar; Jogos Cooperativos.

\begin{abstract}
The approach to cooperative games comprises collective actions based on affective values and human social development. In this sense, the present article is problematic: What is the importance of cooperative games in school education classes in the student's social development? Thus, the study aimed at presenting the historical process, pointing out the contributions in school physical education classes, emphasizing the importance as content of school physical education, reporting the role of the teacher in the inclusion process regarding cooperative games. In view of this, the research comes from an updated bibliographical review. The researched aspects show that the cooperative games implemented in school physical
\end{abstract}

\footnotetext{
${ }^{1}$ Licenciada em Educação Física pelo Centro Universitário Unijorge. Membro do Núcleo de Estudos e Pesquisa em Educação Física.

E-mail: jakilima86@gmail.com

ORCID: https://orcid.org/0000-0003-4957-6556

2 Doutora em Ciências da Educação. Professora na Secretaria Municipal de Educação da Prefeitura Municipal de Salvador. Docente no Centro Universitário UNIJORGE e Centro Universitário UNINASSAU. Sócia efetiva da Associação Brasileira de Psicomotricidade. Líder do Núcleo de Estudos e Pesquisa em Educação Física.

Contato: janerodella@hotmail.com

ORCID: https://orcid.org/0000-0001-5367-1973
} 
education classes influence in a positive and transforming way, taking into consideration the student as the main object to be reached with the mission of putting into practice all acquired social cooperation, regardless of the social space in which he/she is inserted.

Keywords: Physical Education; School; Cooperative Games

\section{Resumen}

El enfoque de los juegos cooperativos comprende acciones colectivas basadas en los valores afectivos y el desarrollo social humano. En este sentido, el presente artículo es problemático: ¿Cuál es la importancia de los juegos cooperativos en las clases de educación escolar en el desarrollo social del alumno? Así, el estudio tuvo como objetivo presentar el proceso histórico, señalando los aportes en las clases de educación física escolar, enfatizando la importancia como contenido de la educación física escolar, reportando el rol del docente en el proceso de inclusión en torno a los juegos cooperativos. En vista de esto, la investigación proviene de una revisión bibliográfica actualizada. Los aspectos investigados muestran que los juegos cooperativos implementados en las clases de educación física escolar influyen de manera positiva y transformadora, tomando en consideración al alumno como el principal objeto a alcanzar con la misión de poner en práctica toda la cooperación social adquirida, independientemente de la naturaleza social. espacio en el que se inserta.

Palabras clave: Educación Física; Escuela; Juegos Cooperativos.

\section{Introdução}

O jogo fundamente-se de uma visão criativa que resulta em comportamentos e nas relações sociais. O termo "jogo" está relacionado a múltiplos conceitos conforme o cenário a ser cometido, facilitando a compreensão nas regras, na qual o esporte não permite, acometendo diferentes espaços, formas de se organizar e manifestar (MALDONADO et al., 2017). Com base na proposta dos Parâmetros Curriculares Nacionais (PCN, 1997), os jogos fazem parte dos conteúdos da educação física escolar, organizados em blocos inter-relacionados. Assim, atuando em caráter competitivo, cooperativo ou recreativo com objetivo de desenvolver habilidades corporais e com propósito sócio- afetivo.

Os jogos cooperativos encontram-se no contexto escolar como agente facilitador do processo de integralidade do indivíduo na sociedade, trabalhando princípios com respeito, solidariedade e a cooperação em diferentes espaços de convívio social (QUERINI, 2013). Para Silva e Pines Junior (2017, p. 61), os jogos cooperativos podem ser considerados: "[...] fundamentais na busca de uma educação integral do ser humano, desenvolvendo autonomia, senso crítico, sentimentos de aceitação e autoestima, colaborando assim na formação crítica e reflexiva". 
Nessa perspectiva ligada a temática, o jogo cooperativo viabiliza estímulos reflexivos, as quais promovem valores humanos, ressalta-se os jogos como ferramenta de grande importância no processo educacional (BROTTO, 2013). Nesse sentido, os jogos tornam-se relevante no processo de desenvolvimento social do educando.

Diante desse contexto, problematiza-se neste artigo: Qual a importância dos jogos cooperativos nas aulas de educação física escolar no desenvolvimento social do aluno? Deste modo, a pesquisa objetiva-se, como ponto central compreender a importância dos jogos cooperativos nas aulas de educação física escolar no desenvolvimento social do aluno.

O presente artigo tem como fundamento apresentar a importância dos jogos cooperativos escolar no desenvolvimento do aluno, assim a temática apontará o desenvolvimento do sentimento coletivo e humano no processo de cooperação e integração por meio de jogos. Desta forma, com base em estudos, espera-se despertar e contribuir com os elementos que fomentam a participação e desenvolvimento social em prol do grupo.

\section{Metodologia}

A metodologia empregada no presente estudo fundamenta-se de uma revisão bibliográfica. De acordo com Marconi e Lakatos (2017), a revisão bibliográfica é considerada o principal apoio para realização de uma pesquisa, seja para atestar ou contrapor resultados de determinadas fontes de pesquisas.

Para a verificação de dados, foram realizadas pesquisas através de livros, cartilhas, artigos científicos consultados mediante as ferramentas do banco de dados dos periódicos CAPES, The Scientific Electronic Library Online (Scielo) e portal de informações do Ministério da Educação (MEC). Vale ressaltar que os Parâmetros Curriculares Nacionais, que até dado momento não foram atualizados, todavia, sua inclusão no presente artigo torna-se um documento com informações relevantes, assim, contribuindo para elaboração da pesquisa. Utilizaram-se descritores como: "educação física", "escolar", jogos cooperativos". 
Após uma leitura dinâmica do material, foram utilizados 10 artigos correspondentes aos anos de 2012 a 2019, como critérios de inclusão que permitirá compreender e analisar os conhecimentos culturais e científicos do tema investigado, em vista disso, os critérios de exclusão foram baseados em meio aos artigos e/ou materiais levantados fora do corte temporal, na qual afastavam-se dos objetivos a serem compreendidos na construção estrutural do artigo.

\section{Jogos cooperativos nas aulas de educação física escolar no desenvolvimento social do aluno}

\subsection{Breve histórico dos jogos cooperativos}

Os jogos cooperativos ao contrário do que se pensa encontra-se inserido na nossa sociedade por décadas, na qual eram praticadas por comunidades tribais em encontros, em culto referente a vida da humanidade (QUERINE, 2013). Portanto, eventualmente considera-se que o jogo veio permitindo-se a uma transformação até que se chegasse à um contexto educacional com inúmeros objetivos.

De acordo com Souza Santos e Santos (2017), por volta da década de 1950, cria-se o primeiro material voltado para os jogos cooperativos intitulado como: "O manual dos novos jogos cooperativos," elaborado pelo educador Ted Lentz com a colaboração da também educadora Ruth Cornelius, por consequência ambos visavam-se um proposito superior nas relações humanas através do jogo tornando-se reconhecido em outros países.

No campo da pesquisa, factualmente o professor canadense Terry Orlick é reconhecido pelo seu trabalho, apresentando-se o tema relacionando o jogo e as características cooperativas e os efeitos que transforma a sociedade ocidental (PALMIERI, 2015).

Essa mesma concepção foi citada por Souza Santos e Santos (2017, p. 8), quando afirmam que "Este serve de inspiração para muitas pesquisas sobre o tema. Orlick é a pessoa que introduziu os Jogos Cooperativos na Educação, com seu trabalho na Educação Infantil do Canadá" e portanto, a história integralizada e organizada com informações dos jogos cooperativos foram descritas por 
Orlick de modo inovador para que fosse compartilhada e desenvolvidas práticas a partir da educação.

No Brasil, as primeiras ações dos jogos cooperativos surgiram por volta de 1950 (BENTIVOGLIO; RIBEIRO, 2013), portanto foi a partir de 1980 na capital paulista, de certo modo, que suas práticas foram exploradas (PALMIERI, 2015).

Conforme Bentivoglio e Ribeiro (2013), no cenário nacional, os jogos cooperativos aponta como referência Fábio Otizi Brotto, estudioso na área da pedagogia da cooperação, responsável por criar projetos educacionais cooperativistas e responsáveis pela publicação de estudos e materiais didáticos, assim considerado o grande precursor dos jogos cooperativos no Brasil, com ênfase pautada na pedagogia e ética.

Desta forma, os autores acima concluem que os jogos cooperativos possuem um histórico que:

[...] apresentam suas primeiras manifestações já na antiguidade, porém no mundo contemporâneo, especificamente no nosso país, a abordagem dos jogos cooperativos vem crescendo, porém suas publicações são bastante novas e ainda muito limitadas. (BENTIVOGLIO; RIBEIRO, 2013, p. 5)

Esse é um ponto importante a ser discutido, no qual cria-se paradigmas através dos estudos, tendo como panorama ideias que ao longo dos anos foram construídas, ampliando-se o campo de pesquisa da temática apresentada.

\subsection{As contribuições dos jogos cooperativos nas aulas de educação física escolar para o desenvolvimento social do aluno}

Os jogos cooperativos apresentam-se por meio de características substanciais com o arremate de ações coletivas nas relações sociais, tornando-se o jogo numa grande ferramenta para estimular os alunos nas aulas de educação física escolar (SILVA et al., 2012). Deste modo, de acordo com Fonseca e Silva (2013) leva-se em consideração os alunos a realizar uma autorreflexão acerca do comportamento com o grupo nos espaços coletivos, sentindo-se incluídos integralmente no ambiente escolar. 
Os jogos cooperativos são jogos inclusivos com o intuito de aproximação do outro e consigo mesmo, na qual são desenvolvidas pelos participantes competências e habilidades, seja no aspecto emocional ou motor (QUERINI, 2013). Desta forma, a autora segue acrescentando que os jogos cooperativos contribuem para:

[...] trabalhar o aspecto da corporeidade no seu real significado, ou seja,
propiciando aos alunos oportunidade de vivenciarem os mais diversos gestos,
expressões e movimentos. Ter a possibilidade de se relacionar com seus
colegas e consigo mesmo através do corpo. Ensinar e aprender diversas
culturas corporais, sem a necessidade da padronização e ou classificação de
movimentos. Através dos jogos as crianças e jovens vivenciam o seu
cotidiano, incorporando valores, conseguem planejar, aprendem conceitos e
desenvolvem a imaginação, além de incentivar a criatividade dos alunos.
(QUERINI, 2013, p. 12)

Segundo Almeida (2019), os jogos cooperativos tem um significado importante para o desenvolvimento social e pessoal, com objetivo Plural, enfatiza-se a transformação de comportamento nas relações humanas, onde não se sustenta em colecionar vitórias, mas sim na evolução individual e coletiva, resultando na autoconfiança sem se preocupar com o certo e errado.

Ainda segundo o autor, demais contribuições podem ser proporcionada através dos jogos, destaca-se que "Desenvolver a cooperação, com a intenção de melhorar a percepção do ambiente geográfico, pode tornar o indivíduo responsável, pode motiválo a agir de forma coerente" (ALMEIDA, 2019, p. 658), deste modo os jogos cooperativos só demonstram suas atribuições qualitativas de transformação e conhecimento para o convívio entre pessoas e espaços.

Para o principal estudioso no Brasil (LOVISOLO; BORGES; MUNIZ, 2013), Brotto (2013), afirma que os jogos cooperativos podem ser comparados a uma " arquitetura do jogo" que integra visão de valores pessoais e grupais que conta com a participação ampla na comunicação, formulação e flexibilização do jogo e no processo de aprendizagem, resultando-se em valorizar o outro e a si mesmo, causando aos participantes sensação de contentamento coletivo, isto é, não visando resultados significativos, mas sim, para que todos vivencie o jogo viabilizando oportunidades.

Ainda de acordo com o autor, algumas habilidades humanas podem ser estimuladas através dos jogos cooperativos como: 
Aprender a solucionar problemas, encontrar soluções positivas, dialogar, desenvolver e valorizar as virtudes, descobrir potenciais, assumir responsabilidades, sustentar um clima de bom humor, descontração e ao mesmo tempo, manter-se concentrado e flexível; são habilidades fundamentais para superar crises e dificuldades. (BROTTO, 2013, p. 12)

De acordo com os autores Souza Santos e Santos (2017) em seu artigo publicado pela Revista Eletrônica Científica Inovação e Tecnologia (RECIT) 9 entre 10 professores questionados afirmam que os jogos cooperativos podem contribuir de forma considerável desenvolvimento para formação humana e valores emocionais.

Baseado no exposto, os jogos cooperativos contribuem para as aulas de educação física, dos quais, intensificam valores qualitativos, do mesmo modo, trabalha-se como agente transformador e inclusivo (FONSECA; SILVA, 2013). À vista disso, empenha-se em buscar caminhos para equidade com práticas pedagógicas inovadoras, nas quais surtem efeitos positivos no desenvolvimento e no bem estar social do aluno.

\subsection{O papel do professor no processo de inclusão nos jogos cooperativos nas aulas de educação física}

O compromisso com a prática docente está eminentemente associada a prática pedagógica aplicada (FREIRE, 2018), e pode estar associada a grande figura representativa que o professor desempenha perante os alunos (DARIDO; SOUZA JÚNIOR, 2013). Deste modo, o "saber fazer" compõe uma bagagem de conhecimentos que o professor alcança em diferentes dimensões presentes na prática de ensino, proveniente da própria experiência vivenciada nas aulas.

Partindo do ponto da inclusão, em que o professor apresenta desafios constantes, Darido e Souza Júnior (2013, p.18) questionam contestando que "[...] quando o professor desenvolve efetivamente uma atitude inclusiva? Quando apoia, estimula, incentiva, valoriza, promove e acolhe o estudante". Portanto, todos os derivados da atitude inclusiva exposta, compreendem-se as condições que compõe as características dos jogos cooperativos.

Almeida (2019, p. 671) faz referência ao jogo cooperativo no ambiente escolar e as atribuições do professor acerca do que o antecede. 
[...] O professor, antes de iniciar algum jogo cooperativo, constrói um espaço de interlocução, no qual esclarece, por meio do estabelecimento da organização espacial e das intervenções ao longo do jogo, as condições em que ocorrerá a participação dos integrantes; assim, ele possibilita ao aluno manifestar-se- no jogo dialético, na troca de interlocutores.

Diante do exposto, o autor ainda completa:

[...] é papel do educador que busca imprimir, na comunidade escolar, o diálogo como instrumento diário, a fim de proporcionar aos alunos a construção de laços de confiança e a compreensão de que, da mesma forma que os conflitos são inseparáveis do processo dialógico, também fazem parte do processo de crescimento e maturidade de cada indivíduo. (ALMEIDA, 2019, p. 700)

Em outra perspectiva, ao trabalhar-se com os jogos cooperativos nas aulas o professor pode-se adotar iniciativas como a utilização de sociograma como ferramenta de análise de comportamento entre os participantes, com o objetivo de acompanhar o processo de integração de cada indivíduo partindo das suas particularidades (FERNÁNDEZ-RíO et al., 2015). Os mesmos autores (2015, p. 208) ainda reforçam "[...] o professor intervém no processo observando, proporcionando feedback e direcionando a ação de acordo com que acontece [...]".

Deste modo, esse tipo de método de observação durante a aplicação dos jogos cooperativos nas aulas de educação física escolar possibilita que o professor compreenda a que nível encontra-se o seu trabalho no processo de inclusão.

O envolvimento do professor na ação no processo de ensino aprendizagem nos jogos cooperativos enfatizados por Brotto (2013, p. 90) diz que "incentivando e valorizando a inclusão de todos, respeitando as diferentes possibilidades de participação", portanto, será necessário o professor observar como essa dinâmica do jogo acontece dentro de uma proposta pedagógica embasada na sua forma de atuação e nas necessidades de quem o joga.

Palmieri (2015) afirma que o educador com sua experiência de transformação pedagógica e mediador pelo conhecimento das práticas, oportuniza incentiva o aluno a empoderar-se por meio de valores proposto nos jogos cooperativos, objetivando-se em uma aprendizagem construtivista.

Os jogos cooperativos e suas características baseadas em valores humanos, adentra no processo de inclusão que são trabalhados em forma conjunta por professor e aluno (QUIRINE, 2013). Desta forma, resulta em uma troca mútua de 
conhecimentos e experiências contidas e as recém adquiridas no decorrer do processo, partindo da vivência individual de cada indivíduo.

Em síntese, apresenta-se o professor em sua essência possuir aspectos que o identifica como mediador influente nas ideias e ações no processo didático/pedagógico inerente ao papel da inclusão. Assim, ao introduzir os jogos cooperativos como ferramenta moderadora socioeducativa a fim de contemplar a todos, independentemente de estado físico ou social, no qual o principal objetivo é a formação crítica-reflexiva do indivíduo para além dos muros da escola.

\subsection{Os jogos cooperativos como conteúdo da educação física escolar}

Os Parâmetros Curriculares Nacionais (1997) instrumentam-se em direcionar o professor na organização e na apresentação das práticas contidas nos blocos de conteúdos da educação física de acordo com os ciclos de ensino, objetivando-se em traçar metas com resultado eficaz que auxilie no conhecimento e desenvolvimento do educando.

Seguida dessa ideia, Almeida (2019) reforça que os Parâmetros Curriculares Nacionais:

[...] estabelecem algumas diretrizes que buscam assegurar que o professor de educação física favoreça o desenvolvimento da autonomia pessoal, na medida em que ele trabalha a dimensão das aquisições fundamentais do indivíduo e da cidadania. Ou seja, as atividades físicas devem capacitar os alunos na identificação das próprias qualidades e dificuldades, nas práticas da disciplina, respeitando seus limites e dos demais colegas. (ALMEIDA, 2019, P.449)

Visto que, as dimensões dos conteúdos, especificamente do bloco relacionado aos jogos Darido e Rangel (2019, p.19) baseados nos Parâmetros Nacionais Curriculares enfatiza que "[...] aspectos conceituais, procedimentais e atitudinais [...]", como importantes dimensões aplicadas baseadas nos conteúdos, a fim de orientar o professor a compreender o andamento do processo de ensino e aprendizagem por meio de respostas do próprio aluno.

Ainda de acordo com os Parâmetros Curriculares Nacionais (1997), o jogo de natureza cooperativa possibilita em suas práticas flexibilização das regras, adaptação tanto no espaço físico ou material sem limites de participantes. 
Visto o exposto, vale ressaltar que a Base Nacional Comum Curricular (2013, p. 214) aponta que "é importante fazer uma distinção entre jogo como conteúdo especifico e jogo como ferramenta auxiliar de ensino", e portanto, deverá estar alinhada ao contexto de adaptação do jogo de acordo com as necessidades das aulas planejadas.

Como conteúdo básico da educação física escolar, os jogos cooperativos caracterizam-se por métodos de ensino da cultura corporal (BENTIVOGLIO; RIBEIRO, 2013), que por sua vez busca-se através do conhecimento adquirido passando a entender as necessidades de modo geral inseridas no contexto social de cada aluno.

Essa mesma visão foi apontada por Querini (2013), quando afirma que os jogos cooperativos por meio da corporeidade e movimento pode-se conhecer diferentes culturas corporais durante o processo de ensino e aprendizagem. Desta forma, possibilita-se os alunos a adquirir experiências no que diz respeito a diversidade de movimentos sem se preocupar com técnicas e refinamento que a cultura do movimento muitas das vezes propõe em seu universo como conteúdo da educação física. Resultando-se na motivação do aluno a cada vez mais participar das atividades proposta pelo professor.

Assim sendo, os conteúdos pautados na inclusão social e humana do aluno mediante as práticas pedagógicas usadas pelo professor, percebe-se durante o decorrer da compreensão sobre os jogos cooperativos que o mesmo possui um papel fundamental no processo educacional no que diz respeito à educação física escolar. Darido e Rangel (2019, p. 159) exprime: "A educação física, ao considerar o jogo conteúdo, colabora para que o mesmo continue a ser transmitido de geração a geração, alicerçando esse patrimônio cultural tão importante para humanidade".

Vista disso, a inserção dos jogos cooperativos como componente dos conteúdos da educação física escolar resulta-se na importância em um universo de possibilidades pedagógicas, no qual engloba-se o saber cooperar, o saber respeitar e conviver com as diferenças em diversos contextos da sociedade.

\section{Considerações finais}


Nota-se no decorrer do artigo que os jogos cooperativos vêm contribuindo de modo relevante dentro do contexto escolar nas aulas de educação física, podendo-se criar processos facilitadores de desenvolvimento humano e social. Deste modo, a pesquisa partiu de uma inquietação para que se busque compreender melhor a funcionalidade no que diz respeito à temática.

Este estudo identificou a captação das origens e processos de conhecimento dos jogos cooperativos, seguindo suas propostas nas aulas da educação física escolar, demonstrando sua importância e contribuição através do trabalho docente alinhados as práticas pedagógicas usadas como ferramenta dos conteúdos.

Em síntese, constata-se que os jogos cooperativos escolar possibilitam uma troca de vivência intrínseca no processo de ensino-aprendizagem. Portanto, apresenta-se como projeto de ação dentro do contexto escolar que resulta na transformação, possibilidades, conhecimentos de habilidades e valores educacionais e sociais.

A partir de levantamentos bibliográficos, levando-se em consideração a uma necessidade de possibilitar um estudo mais aprofundado que norteia a importância do tema. Visto o exposto, a presente artigo dispõe de ações que podem colaborar diretamente no trabalho de extensão na elaboração de outros estudos, contemplando a área da educação e recreação, visando maneiras de intervenções inovadoras em prol da cooperação tendo como resultado o desenvolvimento socioeducativo.

\section{Referências}

ALMEIDA, C. J. S. Jogos Cooperativos e sua Contribuição em Situações de Vulnerabilidade Social. 1. ed. São Paulo: Phorte , 2019.

BENTIVOGLIO, Mauricio; RIBEIRO, Paulo Sérgio. A contribuição dos jogos cooperativos enquanto conteúdo básico da educação física escolar. Os desafios da escola pública paranaense na perspectiva do professor PDE, Paraná , v. 1, n. 1, p. 1-21, ago./2013. Disponível em:http://www.diaadiaeducacao.pr.gov.br/portals/cadernospde/pdebusca/producoes pde/2013/2013_uepg_edfis_artigo_mauricio_bentivoglio.pdf. Acesso em: 16 set. 2020. 
BRASIL. Ministério da Educação. Parâmetros Curriculares Nacionais. Disponível em: http://portal.mec.gov.br/seb/arquivos/pdf/livro07.pdf. Acesso em: 24 mai. 2020.

BROTTO, Fabio Otuzi. Jogos Cooperativos: O JOGO E O ESPORTE COMO UM EXERCICIO DE CONVIVENCIA . 4. ed. São Paulo: Palas Athena, 2013. p. 1-187.

DARIDO, Suraya Cristina; SOUZA JÚNIOR, Osmar Moreira de. Para Ensinar Educação Física: possibilidades de intervenção na escola. 7. ed. Campinas: Papirus, 2013. 348 p.

DARIDO, Suraya Cristina; RANGEL, I. C. A. Educação Física na escola: implicações para a prática pedagógica. 2. ed. Rio de Janeiro: Guanabara Koogan, 2019. p. 2-286.

FERNÁNDEZ-RÍO, J. et al. Atividades e Jogos Cooperativos. 1. ed. Petrópolis, Rio de Janeiro: Vozes, 2015. p. 1-372.

FONSECA, F. R. D; SILVA, E. A. P. C. D. Os jogos cooperativos na Educação Física escolar: favorecimento das relações interpessoais. ConScientiae Saúde, São Paulo, v. 12 , n. 3, p. 588-597, dez./2013.

FREIRE, Paulo. PEDAGOGIA DA AUTONOMIA: saberes Necessários à Prática Educativa. 56. ed. Rio de Janeiro/São Paulo: Paz e Terra, 2018. p. 11-138.

LOVISOLO, Hugo Rodolfo; BORGES, C. N. F; MUNIZ, Igor Barbarioli. Competição e cooperação: na procura do equilíbrio. Revista Brasileira De Ciência Do Esporte, Florianópolis, v. 35, n. 1, p. 129-143, jan./2013. Disponível em: https://www.scielo.br/scielo.php?script=sci_arttext\&pid=S0101-32892013000100011. Acesso em: 25 nov. 2020.

MALDONADO, D. et al. A brincadeira e o jogo no currículo da educação física: a concepção apresentada na versão preliminar da base nacional comum curricular. LICERE - Revista do Programa de Pós-graduação Interdisciplinar em Estudos do Lazer, Belo Horizonte, v. 20, n. 4, p. 1-34, set./2017. Disponível em: https://periodicos.ufmg.br/index.php/licere/article/view/1730/1198. Acesso em: 24 mai. 2020.

MARCONI, M. D. A; LAKATOS, Eva Maria. Fundamentos de Metodologia Científica . 8. ed. São Paulo: Atlas, 2017. p. 148.

MEC. Base Nacional Comum Curricular - Educação é Base. Disponível em: http://basenacionalcomum.mec.gov.br/images/BNCC_EI_EF_110518_versaofinal_sit e.pdf. Acesso em: 11 out. 2020.

PALMIERI, M. W. A. R. Jogos cooperativos e a promoção da cooperação na educação infantil. Revista Quadrimestral da Associação Brasileira de Psicologia Escolar e Educacional, São Paulo, v. 19, n. 2, p. 243-252, mai./2015. Disponível em: https://www.scielo.br/pdf/pee/v19n2/2175-3539-pee-19-02-00243.pdf. Acesso em: 14 set. 2020. 
QUERINI, Marizete. Jogos Cooperativos: Nova Tendência na Educação Física Escolar. Os desafios da escola pública paranaense na perspectiva do professor PDE, Paraná, v. 2, n. 2, p. 1-48, out./2013.

SOUZA SANTOS, Rogério de; SANTOS, Ricardo dos. Jogos cooperativos no processo de ensino e aprendizagem na educação física. Revista Eletrônica Científica Inovação e Tecnologia, Paraná, v. 8, n. 16, p. 1-21, nov. 2017. Disponível em: https://periodicos.utfpr.edu.br/recit/article/view/e-7390/pdf\#. Acesso em: 13 set. 2020.

SILVA, Tiago Aquino da Costa e; PINES JUNIOR, Alipio Rodrigues. Jogos e brincadeiras: Ações lúdicas nas escolas, ruas, hotéis, festas, parques e em família. Petrópolis: Vozes, 2017. 177 p.

SILVA, J. K. F. D. et al. Jogos cooperativos: Contribuição na escola como meio socializador entre crianças do ensino fundamental. Motrivivência, UFPR- Paraná, v. 24, n. 39, p. 195-205, dez./2012. Disponível em: https://periodicos.ufsc.br/index.php/motrivivencia/article/view/21758042.2012v24n39p195/23405. Acesso em: 9 set. 2020.

Manuscrito recebido em: 06 de novembro de 2020 Aprovado em: 22 de dezembro de 2020 Publicado em: 22 de dezembro de 2020 